\title{
Formation mechanism, structural characterization, optical properties and photocatalytic activity of hierarchically arranged sisal-like $\mathrm{ZnO}$ architectures
}

\author{
Fen $\mathrm{Xu}^{\mathrm{a}}$, Gao-Hui $\mathrm{Du}^{\mathrm{b}}$, Matej Halasa ${ }^{\mathrm{a}}$, Bao-Lian $\mathrm{Su}^{\mathrm{a}, *}$ \\ ${ }^{a}$ Laboratory of Inorganic Materials Chemistry, The University of Namur (FUNDP), 61 rue de Bruxelles, B-5000 Namur, Belgium \\ ${ }^{\mathrm{b}}$ Electron Microscopy for Materials Research, University of Antwerp (RUCA), Groenenborgerlann 171, B-2020 Antwerp, Belgium
}

Received 18 April 2006; in final form 14 May 2006

Available online 2 June 2006

\begin{abstract}
A simple low-temperature solution-based self-construction approach has been demonstrated for fabricating the highly uniform assembly of $\mathrm{ZnO}$ nanocones with much higher aspect ratio, in which a highly non-equilibrium chemical environment favors for the large-scale generation of the complex architectures mimicking the sisal-like structures. The formation mechanism has been studied at molecular level. The optical and photocatalytic properties of the as-synthesized product have been correlated with their chemical composition, morphology and structural features. These sisal-like $\mathrm{ZnO}$ nanocone assemblies have shown a strong UV emission with a broad blue emission band and a high photocatalytic activity in decomposition of polyaromatics, suggesting their potentials in light and field emission and environmental applications.
\end{abstract}

(C) 2006 Elsevier B.V. All rights reserved.

\section{Introduction}

Synthesis of binary oxide nanostructures has been a research theme owing to their potential applications in constructing nanoscale electric and optoelectronic devices $[1,2]$. Critical to the properties and behaviour of these potential devices are the crystallinity, stoichiometry, size, shape and structure of these building blocks [3,4]. Different one-dimensional (1D) $\mathrm{ZnO}$ nanostructures have been prepared for fundamental studies of the physical properties $[1,4,5]$ as well as for the widespread use in sensors [6], optoelectronics [7], field emission [8], solar cells [9], and surface acoustic waveguides [10]. Nanocones emerge as a new kind of $1 \mathrm{D}$ nanostructures that is even superior to nanotubes, nanowires, and nanobelts in some aspects $[11,12]$. Nanocones are more advantageous candidates for the scanning probes and field emitters due to their sharp point for easy

\footnotetext{
${ }^{*}$ Corresponding author. Fax: +3281725414 .

E-mail address: bao-lian.su@fundp.ac.be (B.-L. Su).
}

emission of electrons. However, these interesting properties can be deteriorated during growth. To date, most of the reported methods for the fabrication of $\mathrm{ZnO}$ nanocones and their assemblies are restricted to the evaporation and condensation processes (top-down strategy). Although several soft chemical routes have been adopted to obtain aligned $\mathrm{ZnO}$ nanotip/nanorod arrays at a relatively low temperature [13], their reaction processes were complicated. Joo et al., reported a non-hydrolytic ester elimination sol-gel reaction for synthesis of aggregated $\mathrm{ZnO}$ nanocones with low aspect ratio, which needed the various surfactants and the alcoholic reagent, as well as the relatively high temperature of $200-280^{\circ} \mathrm{C}$ [14]. It is still full of promising challenges to develop scalable approaches for fabricating $\mathrm{ZnO}$ micro-assemblies with intricate and precisely controlled features.

Herein, we report a simple bottom-up solution-phase route, involving a highly non-equilibrium chemical environment, to generate the programmed assembly of $\mathrm{ZnO}$ nanocones into sisal-like hierarchical architectures on the surface of the $\mathrm{Zn}$ foil under remarkably mild condition 
$\left(60{ }^{\circ} \mathrm{C}\right)$. The formation mechanism has been studied at molecular level. The synthesized $\mathrm{ZnO}$ nanocones owing to the controlled chemical composition, their specific morphology and structural features have shown quite interesting optical and photocatalytic properties in the decomposition of polyaromatics in comparison with conventional nanorods and nanopowders.

\section{Experimental}

\subsection{Synthesis of sisal-like $\mathrm{ZnO}$ nanocone assemblies}

Zinc sulfate $\left(\mathrm{ZnSO}_{4}\right)$, sodium hydroxide $(\mathrm{NaOH})$, and zinc foil were purchased from Aldrich, and ammonium fluoride $\left(\mathrm{NH}_{4} \mathrm{~F}\right)$ from Merck. All chemicals were used as received without further purification. $\mathrm{Zn}$ foil $(0.25 \mathrm{~mm}$ thick) was cleaned by acetone in an ultrasonic bath for $5 \mathrm{~min}$ and then washed by deionized water for several times. The synthesis of sisal-like $\mathrm{ZnO}$ nanocone assemblies with hierarchical structures was performed in the presence of excessive $\mathrm{NH}_{4} \mathrm{~F}$ by using $\mathrm{ZnSO}_{4}$ solution as zinc precursor. Typically, $40 \mathrm{~mL}$ of $\mathrm{ZnSO}_{4}$ aqueous solution $(0.075 \mathrm{M})$ containing $\mathrm{NH}_{4} \mathrm{~F}$ with $\mathrm{NH}_{4}^{+} / \mathrm{Zn}^{2+}$ molar ratio of 30:1 was slowly adjusted to $\mathrm{pH} \sim 11.70$ by a $\mathrm{NaOH}$ solution $(5 \mathrm{M})$, and then transferred into a Teflon-lined $60-\mathrm{mL}$ capacity autoclave. A $1 \times(1-1.5) \mathrm{cm}^{2} \mathrm{Zn}$ foil was suspended carefully into the solution followed by sealing the autoclave. After $12-15 \mathrm{~h}$ of heating at $60^{\circ} \mathrm{C}$, the foil was removed from the solution, rinsed with deionized water and dried in air for further characterization.

\subsection{Characterization}

The composition and the phase of these as-prepared products were determined by wide-angle X-ray powder diffraction (XRD) pattern, which was recorded on a Philips PW 1820 diffractometer using $\mathrm{Cu} \mathrm{K} \alpha$ radiation. Scanning electron microscopy (SEM) images were carried out with a Philips XL-20 at $20 \mathrm{keV}$. Transmission electron microscopy (TEM), the selected-area electron diffraction (SAED) and high-resolution transmission electron microscopy (HRTEM) were performed on CM30-FEG, operating at $300 \mathrm{kV}$ (equipped with electron energy loss spectroscopy (EELS)). The photoluminescence (PL) was measured by a PELS55-luminescence spectrophotometer, using $325 \mathrm{~nm}$ excitation line of a Xe lamp at room temperature.

\subsection{Photocatalytic activity study}

The photocatalytic activity experiments on the obtained $\mathrm{ZnO}$ nanocones for the decomposition of naphthalene were performed at ambient temperature. The as-prepared $\mathrm{ZnO}$ nanocones (removed from the $\mathrm{Zn}$ foil, $11 \mathrm{mg}$ ) was placed into $66 \mathrm{~mL}$ of a saturated naphthalene aqueous solution $(30 \mathrm{mg} / \mathrm{L}$, water solubility [15]) in a tubular quartz reactor. The reactor was surrounded with six UV lamps (Osram Eversun, L40/79 K, $40 \mathrm{~W}$ ). The reaction mixture was stirred under UV irradiation with the wavelength centered at $350 \mathrm{~nm}$. The analysis of the naphthalene solution concentration in the reactor was performed with a PELS55 luminescence spectrophotometer at $\lambda_{\mathrm{ex}}=280 \mathrm{~nm}$. As a comparison, the activity of $1 \mathrm{D} \mathrm{ZnO}$ nanorods [16] and the commercial $\mathrm{ZnO}$ powders (Aldrich, size $<1 \mu \mathrm{m}, 99.9 \%$ ) was also tested under the same experimental condition.

\section{Results and discussion}

\subsection{Phase and morphology of the obtained assembly of $\mathrm{ZnO}$ nanocones}

Fig. 1a shows the X-ray diffraction (XRD) pattern of the products grown on the $\mathrm{Zn}$ foil, revealing that the as-prepared samples are hexagonal wurtzite $\mathrm{ZnO}$ (space group p6 ${ }_{3} \mathrm{mc}$; JCPDS card No. 36-1451) with the lattice constants of $a=0.325 \mathrm{~nm}$ and $c=0.525 \mathrm{~nm}$. The morphological information of the as-prepared wurtzite-type $\mathrm{ZnO}$ materials was derived from the images of scanning electron microscopy (SEM). Fig. $1 \mathrm{~b}$ is a panoramic SEM image of $\mathrm{ZnO}$ structures, which shows that a large quantity of $\mathrm{ZnO}$ clusters are randomly dispersed on the surface of the $\mathrm{Zn}$ foil. A closer look clearly shows that the clusters are actually sisal-like hierarchical assemblies composed of many $\mathrm{ZnO}$ nanocones (Fig. 1c), and the $\mathrm{ZnO}$ nanocones with very high aspect ratio have sharp tips (Fig. 1d). All nanosisals are almost identical with the uniform size of 15-20 $\mu \mathrm{m}$, showing the highly homogeneous growth of nanocone assemblies.

\subsection{Structural information of $\mathrm{ZnO}$ nanocones}

The unique structures of the generated $\mathrm{ZnO}$ nanocones were further confirmed by the transmission electron microscopy (TEM). Fig. 2a is a low-magnification TEM image, indicating that a typical $\mathrm{ZnO}$ nanocone has a sharp tip of $\sim 90 \mathrm{~nm}$ with a relatively smooth surface. The ripplelike contrast pointed by arrows implies the existence of the strains along the nanocones. The selected-area electron diffraction pattern (the inset of Fig. 2a) reveals single-crystalline nature of the nanocones with $\langle 0001\rangle$ growth direction, which can be indexed as the $[4 \overline{5} 10]$ zone axis of $\mathrm{ZnO}$ crystals. Fig. $2 b$ is an atomic-resolution high-resolution TEM image of the surface of a nanocone, which clearly shows that the $(0001)$ atomic planes (separation: $0.52 \mathrm{~nm}$ ) perpendicular to the nanocone axis and thus indicates that $\langle 0001\rangle$ is the preferred growth direction of these wurtzite-type $\mathrm{ZnO}$ nanocones. An outer layer surrounding the nanocone contains some 'dislocations' pointed by arrows. The EELS spectrum shows that the nanocones only contain $\mathrm{Zn}$ and $\mathrm{O}$ elements, without any other impurity.

\subsection{Influence of growth conditions on $\mathrm{ZnO}$ crystallite structures}

The programmed one-step growth of the unique sisallike $\mathrm{ZnO}$ nanocone assemblies by this simple solution- 
a)

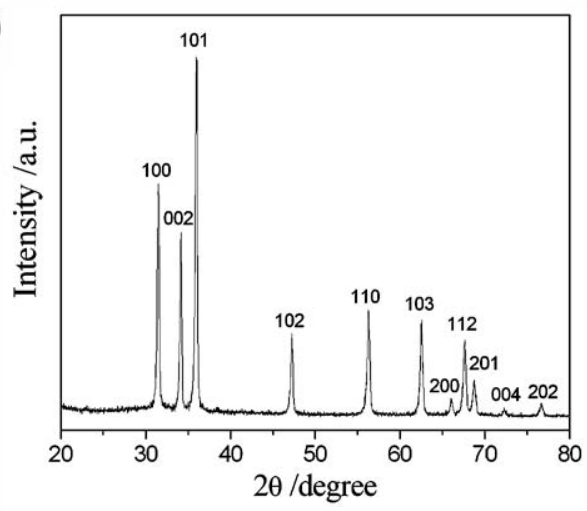

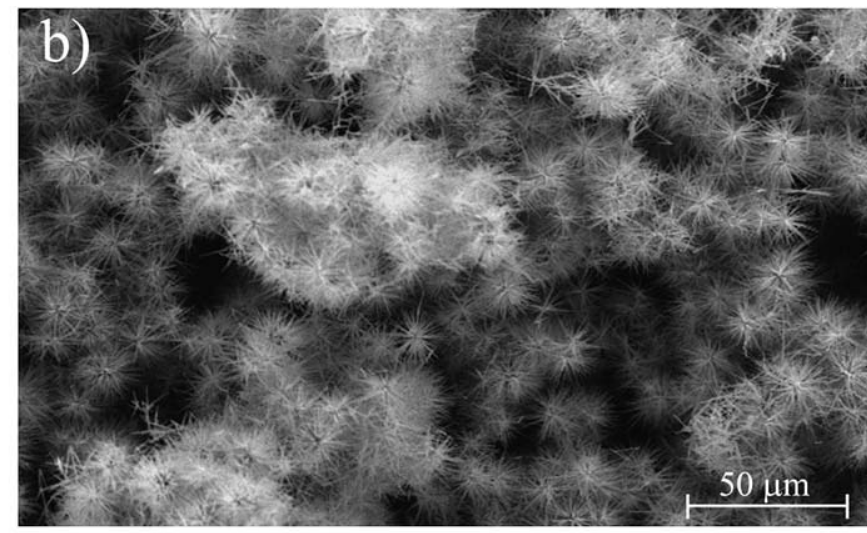

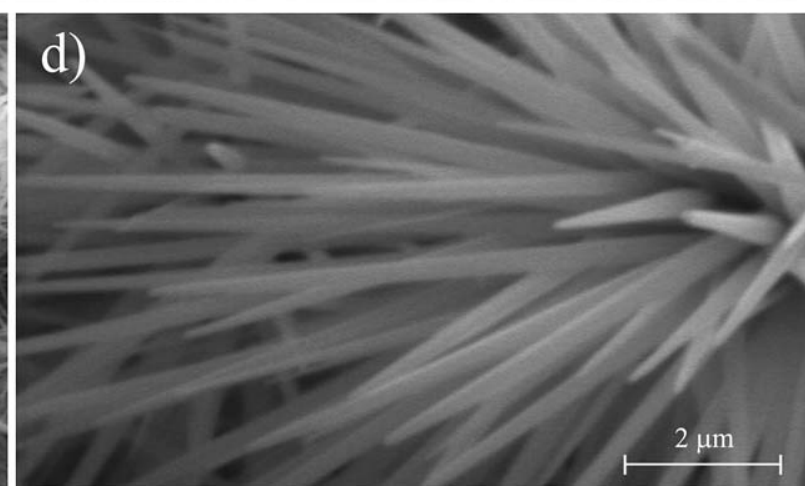

Fig. 1. (a) XRD pattern of the obtained products, indexed to a pure wurtzite ZnO. (b) Overview SEM image, showing a large quantity of ZnO clusters. (c,d) Enlarged SEM images, indicating that the clusters are the nanocone assemblies with the sisal-like hierarchical structures.
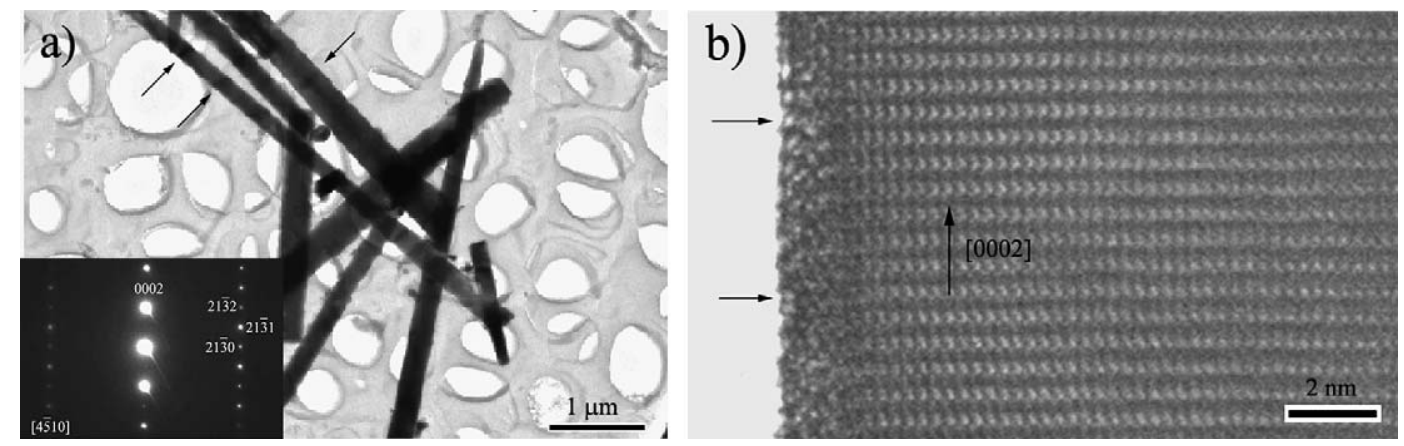

Fig. 2. (a) Low-magnification TEM image of several $\mathrm{ZnO}$ nanocones and the corresponding SAED pattern (inset). (b) High resolution TEM image of a nanocone.

phase route is a spontaneous and self-organized process in the absence of organic agents and/or hard templates (such as $\mathrm{Al}_{2} \mathrm{O}_{3}$ membrane). To understand the self-formation of these novel sisal-like $\mathrm{ZnO}$ nanocone assemblies on the zinc foil surface, a series of reactions were carried out under the different conditions, and it has found that the appearance of sisal-like $\mathrm{ZnO}$ nanocones assemblies is some experimental factors dependent, such as the substrate, the temperature and ammonium fluoride $\left(\mathrm{NH}_{4} \mathrm{~F}\right)$. In the controlled experiments, no $\mathrm{ZnO}$ nanocones assembly was obtained when substituting $\mathrm{Zn}$ foil with $\mathrm{Zn}$ powder or processing in the absence of $\mathrm{Zn}$ foil, which illuminates that the geometry of a $\mathrm{Zn}$ foil obviously favours a more or less unidirectional diffusion of metal ions resulting in the observed vertical growth of $\mathrm{ZnO}$ nanocones [17]. And the structures of the final products have a good relevancy with the reaction temperature. If the synthesis was performed at a temperature as low as $40^{\circ} \mathrm{C}$, little sisal-like $\mathrm{ZnO}$ nanocone assemblies could be obtained, due to the lack of introduction of foreign seed particles onto the substrate at too low temperature. While at an optimized temperature of $60^{\circ} \mathrm{C}$, sisal-like $\mathrm{ZnO}$ nanocone assemblies with hierarchical structures can be produced in a large scale by this simple approach. However, the increase of the temperature to $80^{\circ} \mathrm{C}$ or higher would result in only the uneven $\mathrm{ZnO}$ rods with their diameters changed from $\sim 1.2$ to $\sim 1.5 \mu \mathrm{m}$ (Fig. 3). This clearly indicates that the supply rate of zinc precursors can be turned from low to high level by increas- 

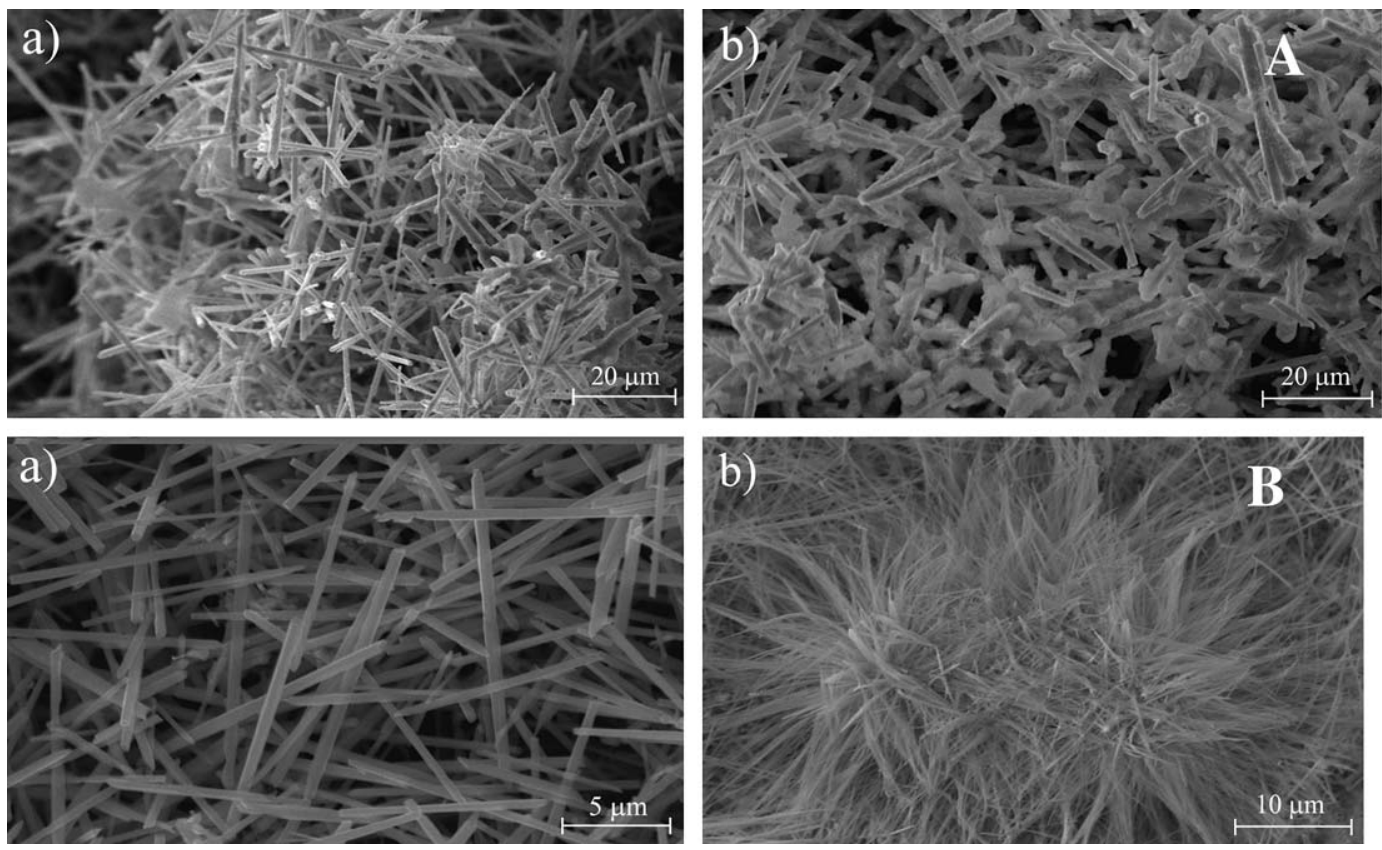

Fig. 3. SEM images: (A) $\mathrm{ZnO}$ structures synthesized at (a) 80 and (b) $100^{\circ} \mathrm{C}$.

(B) $\mathrm{ZnO}$ nanorods (c) obtained in the presence of $\mathrm{NH}_{4} \mathrm{NO}_{3}$ and (d) flowerlike $\mathrm{ZnO}$ nanowires with twin architectures prepared when using $\mathrm{NaF}$.

ing the reaction temperature, which results in the growth of $\mathrm{ZnO}$ nanorods occurring under the kinetically controlled condition, suggesting that the rapid supply of $\mathrm{ZnO}$ precursor favours the formation of nanorod aggregation rather than nanocone assemblies.

Furthermore, the excessive quantity of $\mathrm{NH}_{4} \mathrm{~F}$ is indispensable for the formation of sisal-like $\mathrm{ZnO}$ nanocone assemblies. The deposition rate on the substrate can be reduced because of the strong coordination of the most electronegative $\mathrm{F}^{-}$anions to $\mathrm{Zn}^{2+}$ cations, which would be accompanied by the heterogeneous nucleation $[11,18]$ and thus prefer to the oriented complex architectures, such as sisal-like and flower-like nanostructures. Our controlled experiments also indicate that the cooperation of $\mathrm{NH}_{4}^{+}$and $\mathrm{F}^{-}$would play a crucial role in the appearance of the sisallike structures. Other nanostructures rather than nanocones would be obtained if substituting $\mathrm{NH}_{4} \mathrm{~F}$ with $\mathrm{NH}_{4} \mathrm{NO}_{3}$ or $\mathrm{NaF}$ at the same molar ratios to $\mathrm{Zn}^{2+}$ ions. Typically, the straight $\mathrm{ZnO}$ nanorods would be achieved when $\mathrm{NH}_{4} \mathrm{NO}_{3}$ was used instead of $\mathrm{NH}_{4} \mathrm{~F}$, whilst another interesting flower-like nanowire assembly was prepared in the substitution of $\mathrm{NH}_{4} \mathrm{~F}$ with $\mathrm{NaF}$ (Fig. 4). It appears to be the synergy of $\mathrm{NH}_{4}^{+}$and $\mathrm{F}^{-}$ions that orients the growth direction of nanocrystals. Additionally, there is a progressive decrease in the amount of $\mathrm{ZnO}$ species along the [0001] direction of the growing nanostructures, leading to the formation of nanocones [19]. The growth of $\mathrm{ZnO}$ nanocones, similar to the reported TGC [20], may be decomposed into axial and radial directions, respectively, where the root-based radial growth is a process of continuous formation of additional outside layers while the axial growth simultaneously elongated the formed layers along the axial growth.
Although this synthetic procedure is very simple, the formation mechanism and the self-assembly process seem to be quite complex. The multiple and dynamical interactions strongly control the formation of highly ordered structures. Difference in kinetics (growth rates, adsorption of counter-ions on the growing crystal faces, etc.) are the likely origin $[19,21]$. Both the internal crystal structures and the interaction between $\mathrm{NH}_{4} \mathrm{~F}$ and $\mathrm{Zn}^{2+}$ come into play to engender the formation of sisal-like nanocone assemblies with hierarchical structures in the mineralization process. $\mathrm{ZnO}$ crystals, directed by the coordination of many factors, grow in the direction where the crystalli-

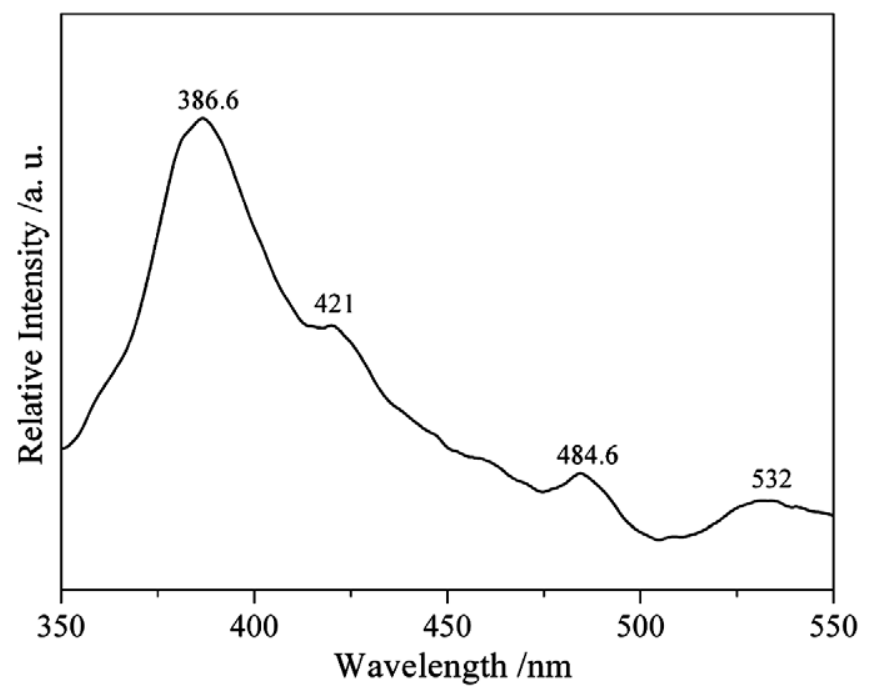

Fig. 4. Photoluminescence spectrum of sisal-like $\mathrm{ZnO}$ nanocone assemblies at room temperature $\left(\lambda_{\mathrm{ex}}=325 \mathrm{~nm}\right)$. 
zation hindrance is weakest. This evidences that in the wellprogrammed highly non-equilibrium environment, the selforganisation of ions in relation to crystal growth can occur just like in a biomineralization process. The interactions between these chemical species would ultimately determine the geometry and distances where they come to equilibrium in a self-assembled system and thus attain the most stable form [22]. However, further investigation is needed to better understand this pseudo biomineralization mechanism of the morphology evolvement.

\subsection{Optical properties}

Photoluminescence (PL) spectroscopy is an effective technique to evaluate both $\mathrm{ZnO}$ defects and its optical property available as a photonic material. Fig. 4 shows a typical room temperature PL spectrum of sisal-like $\mathrm{ZnO}$ nanocone assemblies, where a strong UV emission at $\sim 386.6 \mathrm{~nm}$ dominates with several weak emission peaks at $\sim 421 \mathrm{~nm}, 484.6 \mathrm{~nm}$ and $532 \mathrm{~nm}$, respectively. The strong emission at $\sim 386.6 \mathrm{~nm}(3.22 \mathrm{eV})$ is resulted from the annihilation of free-exciton, and the deep level emission at $\sim 532 \mathrm{~nm}(2.38 \mathrm{eV})$ is generally attributed to the recombination of electron in singly occupied oxygen vacancies with photoexcited holes [23]. The emissions at $\sim 421 \mathrm{~nm}$ $(2.95 \mathrm{eV})$ and $\sim 484.6 \mathrm{~nm}(2.56 \mathrm{eV})$ originate from the electron transition from the level of the ionized oxygen vacancies to the valance band [24]. The sharp excitonic emission and the weak deep level emission peaks indicate that the $\mathrm{ZnO}$ nanocones have high optical property [16], which suggests that the as-prepared $\mathrm{ZnO}$ nanocone assemlies may have potential light and field emission applications.

\subsection{Photocatalytic activity in the decomposition of naphthalene}

The photocatalytic testing has revealed a very high photocatalytic activity of naphthalene degradation (Fig. 5). During the degradation of naphthalene over the asobtained sisal-like $\mathrm{ZnO}$ nanocone assemblies, the concentration of the naphthalene could quickly decrease to $1.8 \%$ after 30-min UV irradiation, and continue down to $<0.3 \%$ when prolonging the irradiation time to $60 \mathrm{~min}$, respectively. In comparison, the concentration of the naphthalene could decrease to $2.1 \%$ after 30-min UV irradiation on the conventional $1 \mathrm{D} \mathrm{ZnO}$ nanorods, which further decrease to $0.36 \%$ after 60 -min irradiation and down to $<0.3 \%$ after 75 -min irradiation. Whereas the commercial $\mathrm{ZnO}$ powders need at least $120 \mathrm{~min}$ to decompose the naphthalene to $<0.3 \%$ of the saturated concentration. Additionally, compared to previously synthesized $\mathrm{ZnO}$ nanowires [25], the photocatalytic activity of the asobtained $\mathrm{ZnO}$ nanocone assemblies is also improved. It is thus obvious that $\mathrm{ZnO}$ nanocones have better photocatalytic properties than $\mathrm{ZnO}$ powders. This enhanced catalytic property could be attributed to the unique surface nanofeatures [26]. These valuable results indicate that the sisal-

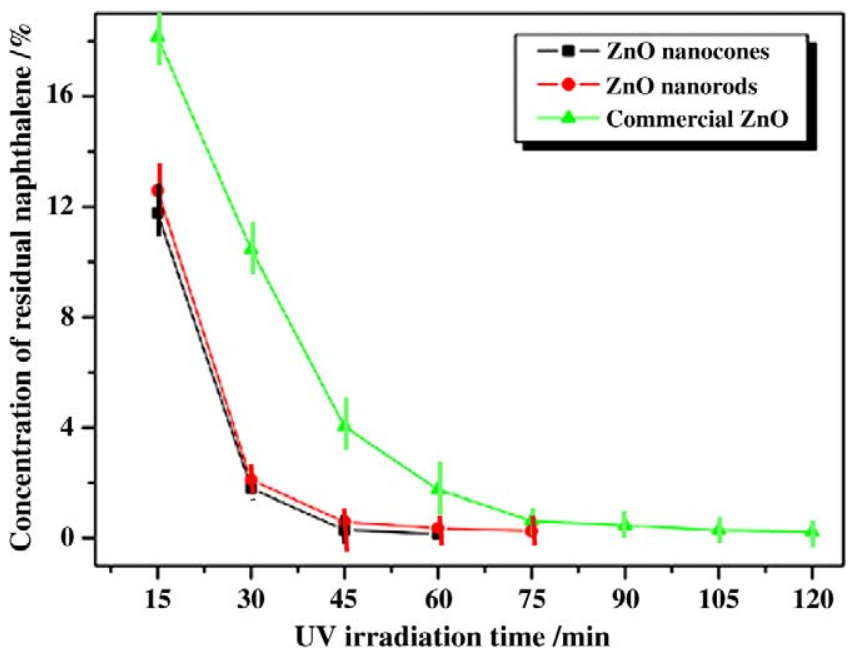

Fig. 5. The concentration of residual naphthalene after UV irradiation at different times over the as-prepared $\mathrm{ZnO}$ nanocones and the pre-obtained $1 \mathrm{D} \mathrm{ZnO}$ nanorods, as well as the commercial $\mathrm{ZnO}$ powders.

like $\mathrm{ZnO}$ nanocone assemblies could have valuable activity in air and waste-water purification.

\section{Conclusions}

A facile solution-phase route has been employed to fabricate the sisal-like hierarchical architectured $\mathrm{ZnO}$ nanocone assemblies on the surface of $\mathrm{Zn}$ foil at $60^{\circ} \mathrm{C}$, involving a highly non-equilibrium chemical environment rather than other extend driving force. The formation and assemblies of nanocones on the surface of zinc foil could be controlled by carefully tuning the reaction parameters. The sharp excitonic emission observed with these $\mathrm{ZnO}$ nanocone assemblies indicate that the $\mathrm{ZnO}$ nanocones have a low defects concentration and high optical properties, which may find great potential in nanoscale devices and systems. And the enhanced photocatalytic properties suggest that these sisal-like $\mathrm{ZnO}$ nanocone assemblies are more compelling for the environmental applications.

\section{Acknowledgements}

This work was performed in the frame of the Belgian Federal Government PAI-IUAP-01/5 Project. F. Xu acknowledges the post-doctoral fellow from the University of Namur.

\section{References}

[1] J.C. Johnson, H.Q. Yan, R.D. Schaller, L.H. Haber, R.J. Saykally, P.D. Yang, J. Phys. Chem. B. 105 (2001) 11387.

[2] C.N.R. Rao, G. Gundiah, F.L. Deepak, A. Govindaraj, A.K. Cheetham, J. Mater. Chem. 14 (2004) 440.

[3] Y.J. Xiong, J.M. McLellan, J.Y. Chen, Y.D. Yin, Z.Y. Li, Y.N. Xia, J. Am. Chem. Soc. 127 (2005) 17118

[4] R.F. Service, Science 276 (1997) 895.

[5] M. Monge, M.L. Kahn, A. Maisonnat, B. Chaudret, Angew. Chem., Int. Ed. 42 (2003) 5321. 
[6] S.C. Minne, S.R. Manalis, C.F. Quate, Appl. Phys. Lett. 67 (1995) 3918.

[7] M.H. Huang et al., Science 292 (2001) 1897.

[8] C.H. Liu et al., Adv. Mater. 15 (2003) 838.

[9] K. Keis, L. Vayssieres, S.E. Lindquist, A. Hagfeldt, Nanostruct. Mater. 12 (1999) 487.

[10] C.R. Gorla, N.W. Emanetoglu, S. Liang, W.E. Mayo, Y. Lu, M. Wraback, H. Shen, J. Appl. Phys. 85 (1999) 2595.

[11] G.Y. Zhang, X. Jiang, E.G. Wang, Science 300 (2003) 472.

[12] Y.B. Li, Y. Bando, D. Golberg, Appl. Phys. Lett. 84 (2004) 3603.

[13] H.D. Yu, Z.P. Zhang, M.Y. Han, X.T. Hao, F.R. Zhu, J. Am. Chem. Soc. 127 (2005) 2378.

[14] J. Joo, S.G. Kwon, J.H. Yu, T. Hyeon, Adv. Mater. 17 (2005) 1873.

[15] C. Richard, P. Boule, J.M. Aubry, J. Photochem. Photobiol. 60 (1991) 235.

[16] Q. Tang, W.J. Zhou, J.M. Shen, W. Zhang, L.F. Kong, Y.T. Qian, Chem. Commun. (2004) 712.
[17] L.Z. Zhang, J.C. Yu, M.S. Mo, L. Wu, Q. Li, K.W. Kwong, J. Am. Chem. Soc. 126 (2004) 8116.

[18] S. Yamabi, H. Imai, J. Mater. Chem. 12 (2002) 3773.

[19] L.E. Jensen, M.T. Björk, S. Jeppesen, A.I. Persson, B.J. Ohlsson, L. Samuelson, Nanoletters 4 (2004) 1961.

[20] G.Y. Zhang, X.D. Bai, E.G. Wang, Phys. Rev. B. 71 (2005) 113411.

[21] K. Govender, D.S. Boyle, P.B. Kenway, P. O'Brien, J. Mater. Chem. 14 (2004) 2575.

[22] G. Ozin, A. Arsenault, Nanochemistry: A Chemical Approach to Nanomaterials, RSC Publishing, 2005 (Chapter 1).

[23] Z.Q. Li, Y. Ding, Y.J. Xiong, Q. Yang, Y. Xie, Chem. Eur. J. 10 (2004) 5823.

[24] D.H. Zhang, Q.P. Wang, Z.Y. Xue, Appl. Surf. Sci. 207 (2004) 20.

[25] F. Xu, Z.Y. Yuan, G.H. Du, T.Z. Ren, C. Bouvy, M. Halasa, B.L. $\mathrm{Su}$, Nanotechnology 17 (2006) 588.

[26] Z.R.R. Tian et al., Nat. Mater. 2 (2003) 821. 